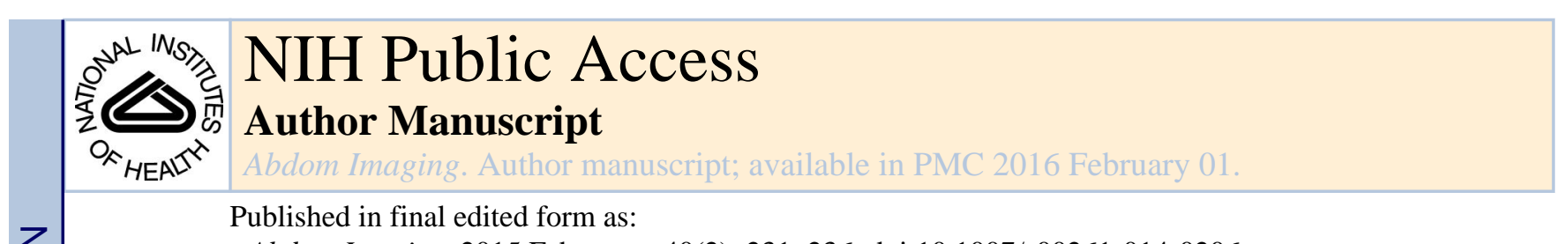

Published in final edited form as:

Abdom Imaging. 2015 February ; 40(2): 231-236. doi:10.1007/s00261-014-0206-x.

\title{
Objective Volumetric Comparison of Room Air versus Carbon Dioxide for Colonic Distention at Screening CT Colonography
}

\author{
James L. Patrick, MD, PhD, Joshua R. Bakke, BS, Peter Bannas, MD, David H. Kim, MD, \\ Meghan G. Lubner, MD, and Perry J. Pickhardt, MD \\ Department of Radiology, University of Wisconsin School of Medicine \& Public Health, Madison, \\ WI
}

\begin{abstract}
Purpose-To objectively compare colonic distention at CT colonography (CTC) achieved with manual room air versus automated low-pressure carbon dioxide using a novel automated volumetric quality assessment tool.
\end{abstract}

Methods-Volumetric analysis was retrospectively performed on CTC studies in 300 asymptomatic adults using an automated quality assessment tool (V3D Colon [beta version], Viatronix). Colonic distention was achieved with room air self-administered to tolerance via handheld pump (mean number of pumps, $39 \pm 32$ ) in 150 individuals (mean age, 59 years; 98 men, 51 women) and via continuous low-pressure automated infusion of carbon dioxide in 150 individuals (mean age, 57 years; 89 men, 61 women). CTC studies in supine and prone position were assessed to determine total colonic volume (luminal gas and fluid). The colonic length along the automated centerline was also recorded to enable calculation of length-adjusted colonic volumes.

Results-The mean total colonic volume ( \pm SD) for individuals receiving room air and carbon dioxide distention was $1809 \pm 514 \mathrm{~mL}$ and $2223 \pm 686 \mathrm{~mL}$, respectively $(\mathrm{p}<0.01)$. The prone position was better distended in $78.7 \%$ (118/150) of cases using room air; whereas, the supine was better in 66.0\% (99/150) of carbon dioxide cases ( $\mathrm{p}<0.01)$. Using a volume threshold of $2000 \mathrm{ml}$, $49(32.7 \%)$ of room air cases and $92(61.3 \%)$ of $\mathrm{CO}_{2}$ cases were above this cut-off. The mean length-adjusted colonic volume $(\mathrm{mL} / \mathrm{cm})$ for the room air and carbon dioxide techniques was $9.9 \pm$ $2.4 \mathrm{~mL} / \mathrm{cm}$ and $11.6 \pm 2.6 \mathrm{~mL} / \mathrm{cm}(\mathrm{p}<0.01)$.

Conclusions-Using automated volumetry allowed quantitative analyses of colonic volumes and objectively confirmed that continuous low-pressure carbon dioxide provides greater overall colonic distention than the manual room air technique at CTC. The supine position demonstrated better distention with carbon dioxide, whereas the prone position was better distended with the room air technique.

Corresponding author: Perry J. Pickhardt, MD, Department of Radiology, University of Wisconsin School of Medicine \& Public Health, E3/311 Clinical Science Center, 600 Highland Ave., Madison, WI 53792-3252, ppickhardt2@ uwhealth.org, phone: 608-263-9028 fax: 608-263-0140. 


\section{Introduction}

There are many factors and technical obstacles that have been addressed to help streamline and optimize performance of CT colonography (CTC). Issues that must be addressed include: bowel preparation, colonic distention, $\mathrm{CT}$ scanning technique, and the rendering software for analysis. ${ }^{1,2}$ Suboptimal performance of any of these areas will degrade sensitivity and specificity for polyp detection at CTC.

Adequate (and preferably optimal) colonic distention is critical for effective lesion detection at CTC. ${ }^{3-8}$ Initially, room air manually delivered from a patient- or staff-controlled simple handheld pump was used to distend the colon. More recently, automated carbon dioxide $\left(\mathrm{CO}_{2}\right)$ delivery systems have become widely available. It has been shown that $\mathrm{CO}_{2}$ has a superior safety profile (due to lower peak pressures) and produces less discomfort postprocedure (due to rapid reabsorption). ${ }^{7-10} \mathrm{CO}_{2}$ systems are also easier to use as they do not require any patient coaching and have a more clearly defined end point. Anecdotally, it has been generally accepted that $\mathrm{CO}_{2}$ produces better and more consistent colonic distention than room air. Through subjective and somewhat crude semi-quantitative scoring systems, it has been suggested that $\mathrm{CO}_{2}$ provides improved colonic distention compared with room air. ${ }^{7,8}$

To our knowledge, no truly objective volumetric quantitative analysis has been performed to compare colonic distention with manually-delivered room air and automatically-delivered $\mathrm{CO}_{2}$. The advent of a novel quantitative volumetric analysis tool now allows for the quantitative evaluation of colonic intra-luminal gas and fluid volumes. ${ }^{11}$ The purpose of this study was to employ this new QA tool to quantitatively measure and compare the differences in colonic distention between patient-controlled room air insufflation and automated $\mathrm{CO}_{2}$ delivery techniques.

\section{Methods and Materials}

\section{Study group}

A retrospective multi-institutional cohort study was performed that was Health Insurance and Portability and Accountability Act compliant, and was IRB approved. The need for specific additional patient consent was waived. A total of 300 asymptomatic patients who underwent CTC screening were selected for volumetric analysis of the colon. The patients consisted of two groups of 150. In the first group (mean height, $162.6 \mathrm{~cm}$.; mean weight, $84.3 \mathrm{Kg}$.; mean BMI 27.8; mean age, 59 years; 98 men, 51 women), colonic distention was achieved using room air via self-administered handheld pump. This asymptomatic room air cohort represents a random subset of the DoD CTC screening trial. ${ }^{12}$ In the second group (mean height, $169.1 \mathrm{~cm}$.; mean weight, $97.7 \mathrm{Kg}$.; mean BMI 30.8; mean age, 57 years; 89 men, 61 women), distention was achieved via low-pressure $\mathrm{CO}_{2}$ delivery. This group represents of subset of asymptomatic individuals who underwent screening within the CTC program at our institution [blinded for review]. To provide a more gender-matched comparison, 50 consecutive women were excluded from this $\mathrm{CO}_{2}$ cohort (originally 200 consecutive patients), resulting in the final 150 patient sample. 


\section{CTC Distention Technique}

Bowel preparation for both patient cohorts consisted of a cathartic agent (sodium phosphate or magnesium citrate) followed by oral contrast tagging as previously described. ${ }^{11}$ All CTC examinations were evaluated online by an experienced CT technologist for quality assurance, with additional input from the interpreting radiologist as needed.

Colonic distention was achieved in the room air $(\mathrm{DoD})$ group through patient-controlled insufflation via a small flexible rectal catheter connected by tubing to a standard air bulb insufflator used for barium enema examination (Fig 1A). The CT technologist coached the patient on self-insufflation and provided assistance if needed. The room air technique began in the left lateral decubitus position followed by supine and prone positioning. The total number of handheld bulb pumps was recorded for both positions (total mean number of pumps, $39 \pm 32$ ).

For the $\mathrm{CO}_{2}$ group, colonic distention was achieved using an automatic low-pressure $\mathrm{CO}_{2}$ delivery device ( $\mathrm{PROTOCO}_{2} \mathrm{~L}$, Bracco Diagnostics) via flexible rectal catheter (Fig 1B). The subject was initially placed in the left lateral decubitus position and an initial volume of 1 to $1.5 \mathrm{~L}$ of $\mathrm{CO}_{2}$ were instilled with the equilibrium pressure set at approximately $17-18$ $\mathrm{mm} \mathrm{Hg}$. The patient was then moved to a right lateral decubitus position until approximately $2.5 \mathrm{~L}$ of total $\mathrm{CO}_{2}$ was delivered. Equilibrium pressure was gradually increased to $25 \mathrm{mmHg}$ during this process. The patient was then placed in the supine position until steady-state equilibrium was achieved. A scout view was then obtained during end-expiration, followed by supine CT image acquisition, assuming adequate distention. The patient was then placed in the prone position and repeat scanning was performed once equilibrium pressure was again achieved.

\section{CTC Acquisition Protocol}

CT image acquisition was obtained in the supine and prone positions using multi-detector CT scanners (GE Healthcare, Waukesha, WI). Scanning technique consisted of 1.25-2.5 $\mathrm{mm}$ collimation with a technique of 25 to $100 \mathrm{mAs}$ (or with tube current modulation), 120 $\mathrm{KV}_{\mathrm{p}}$, and 1-2 mm reconstruction interval. Any decubitus series obtained after the standard supine and prone series were not included for analysis in this study.

\section{Data Analysis}

Volumetric data analysis of colonic distention for both the room air and $\mathrm{CO}_{2}$ cohorts was performed using a novel software application (V3D Colon beta version, Viatronix). The efficacy of this novel software application has been validated by a previous study. ${ }^{11}$ This software has also been internally validated with phantom studies performed by the manufacturer, demonstrating accuracy for volume assessment on the order of 98\%. DICOM data sets were exported to a dedicated CTC workstation for volumetric analysis. The colon segmentation algorithm detects the gas-filled luminal cavity by initial thresholding, and then uses a growing technique to delineate all tagged fluid regions connected to the gas-filled lumen by probing for seed pixels greater than $200 \mathrm{HU}$ along the gravitational direction with defined spatial range constraints. In a final step, the partial volume layer that forms between air and tagged fluid is determined. The processed total colonic lumen consists of gas, tagged 
fluid, and partial volume layer regions. A median filtering technique is applied to the extracted regions to remove morphological irregularity caused by image noise and artifacts. Gas volume and fluid volume are calculated by summing the voxels with selected labels.

Total colonic volume was recorded in each case for the position (supine or prone) with the best overall distention. Fluid and gas volumes were also recorded. Automated colonic length was also generated along the centerline, which was recorded to adjust for potential differences in total colonic volume related to differences in length by calculating lengthadjusted colonic volumes. An empirically-derived target volume threshold of $2000 \mathrm{ml}$ was used as an general indicator of adequate colonic distention, which was derived from previous research ${ }^{11}$.

The Student's t-test was performed to determine whether the absolute and adjusted colonic distention volumes were statistically significant between the room air and $\mathrm{CO}_{2}$ cohorts, with a $\mathrm{p}$ value of less than 0.05 being statistically significant.

\section{Results}

Assessment of total colonic volume using the automated QA tool was performed in all 300 patients without technical failure. Small differences in patient demographics with respect to height $(\mathrm{p}=0.68)$, sex $(\mathrm{p}=0.42)$, weight $(\mathrm{p}=0.66)$ and BMI $(\mathrm{p}=0.20)$ were not statistically significant between the two groups. Only the age difference between the two groups was statistically significant, with the DoD group being older by two years on average $(\mathrm{p}<0.01)$, which is of doubtful clinical significance (Fig 2$)$. The mean overall colonic volume $( \pm$ SD) for individuals receiving patient-controlled room air and automated $\mathrm{CO}_{2}$ was $1809 \pm 513$ $\mathrm{mL}$ and $2223 \pm 686 \mathrm{~mL}$, respectively $(\mathrm{p}<0.01)$ (Figure $3 \mathrm{~A})$. The mean residual fluid $( \pm \mathrm{SD})$ for the room air and $\mathrm{CO}_{2}$ groups was $243 \pm 154 \mathrm{~mL}$ and $163 \pm 133 \mathrm{~mL}$, respectively $(\mathrm{p}<0.01)$ (Figure 3A). The mean colonic gas volume for the room air and $\mathrm{CO}_{2}$ groups $( \pm$ $\mathrm{SD}$ ) was $1576 \pm 430 \mathrm{~mL}$ and $2060 \pm 606 \mathrm{~mL}$, respectively ( $\mathrm{p}<0.01$ ) (Figure $3 \mathrm{~A})$.

Using an empirically-derived total colonic volume threshold of $2000 \mathrm{ml}, 49$ (32.7\%) of the 150 room air cases and $92(61.3 \%)$ of the $150 \mathrm{CO}_{2}$ cases were above this cut-off. Mean colonic length along the centerline was $181 \mathrm{~cm}$ for the room air (DoD) group and $191 \mathrm{~cm}$ for the $\mathrm{CO}_{2}$ group. After adjusting for differences in colon length, the mean adjusted colonic volume $(\mathrm{mL} / \mathrm{cm})$ between the two respective groups was $10 \pm 2 \mathrm{~mL} / \mathrm{cm}$ for the room air technique, and $12 \pm 3 \mathrm{~mL} / \mathrm{cm}$ for $\mathrm{CO}_{2}(\mathrm{p}<0.01)$ (Figure $3 \mathrm{~B}$ ).

Significant differences were noted in terms of which patient position produced better distention according to method. For the room air technique, the prone position produced better distention than the supine in $78.7 \%(118 / 150)$ of patients ( $<<0.01)$; conversely, the supine position was better in 66\% (99/150) of $\mathrm{CO}_{2}$ patients ( $\left.\mathrm{p}<0.01\right)$ (Figure 4). Beyond the derived volumes, qualitative visual differences in the $3 \mathrm{D}$ volume maps between the patient positions for room air and $\mathrm{CO}_{2}$ complemented the numerical volume differences when viewed in a side-by-side fashion (Figure 5). For example, the rectosigmoid region was often relatively under-distended for supine room air cases, whereas suboptimal distention of the transverse colon was generally more apparent on the prone $\mathrm{CO}_{2}$ cases (Figure 5). 


\section{Discussion}

Optimal or at least adequate colonic distention is one of the key parameters for successful CTC evaluation, along with appropriate bowel preparation, CT scanning and robust 3D/2D interpretation software. Inadequate distention is a major factor for important false negative results at CTC, which can be further exacerbated by the other aforementioned quality issues. During the early period after the introduction of CTC, manual room air distention was generally employed due to its ubiquitous availability, low-cost nature, and the longstanding experience with the barium enema. ${ }^{12-14}$ However, as automated $\mathrm{CO}_{2}$ systems developed, certain advantages of this approach over room air became apparent over time. For example, the risk of perforation, albeit very low with manual room air, approached zero with refined low-pressure automated $\mathrm{CO}_{2}$ machines. ${ }^{10} \mathrm{CO}_{2}$ also results in significantly decreased postprocedural discomfort due to its rapid reabsorption through the colon wall, both at CTC and colonoscopy. ${ }^{8,} 15$ In addition, CT technologists familiar with both techniques generally prefer automated $\mathrm{CO}_{2}$ over manual room air insufflation due to a clearer end point for scanning and decreased need for coaching (if patient-controlled). ${ }^{8}$

Prior studies have also shown an overall improvement in colonic distention with automated $\mathrm{CO}_{2}$ compared with room air. ${ }^{7,8}$ However, assessment of distention quality in these studies was based on limited semi-quantitative scoring that sampled only intermittent portions of the colon. Typically, readers subjectively scored segments according to discrete degrees of luminal distention rather than on a continuous scale. Our automated and operator independent QA tool study employed allowed a more objective and absolute measure that takes the entire colonic volume into account. This automated QA tool was recently validated by comparing distention at CTC according to supine, prone, and decubitus positions. ${ }^{11}$ Our findings confirm that automated $\mathrm{CO}_{2}$ provides consistently better distention than manual room air. The improvement in overall distention with $\mathrm{CO}_{2}$ was over $400 \mathrm{ml}$ in volume on average. These results have important implications for diagnostic performance. In conjunction with the other aforementioned advantages concerning safety, comfort, and convenience, automated $\mathrm{CO}_{2}$ clearly represents the preferred method for luminal distention at CTC.

In addition to the difference in overall distention, there was a striking difference in supine versus prone distention. For room air, it stands to reason that the prone position generally demonstrates increased colonic volume, since additional pumps of air are often added after the supine series and colonic absorption of room air is negligible. For $\mathrm{CO}_{2}$, prone distention is likely diminished compared with supine related to partial compression from body girth, which is not overcome by the low-pressure settings. This supine versus prone observation was previously reported by Michel et al. based on subjective assessment. ${ }^{16}$ The decreased distention in the prone position with automated $\mathrm{CO}_{2}$ is further exacerbated by obesity, making decubitus positioning necessary in many of these cases. ${ }^{11,17}$

The approximately $10 \mathrm{~cm}$ difference in mean colonic length between the two groups was unexpected, as they were reasonably well matched asymptomatic screening cohorts. Colonic length does vary somewhat according to gender, age, and even BMI, ${ }^{18}$ and even more substantial changes are seen between groups where colonoscopy is incomplete versus 
complete; ${ }^{19}$ however, most of these factors do not apply for our patient cohorts. It is conceivable that some of the difference was due to foreshortening related to under-distention in the room air cohort, although it is uncertain if any meaningful length change occurs with distention. Even with the length discrepancy between the study groups in our study, colonic distention remained significantly different after adjusting for length.

There are several limitations associated with the study. Most important is the temporal difference between the two cohorts, which was largely unavoidable related to the preferred or available distention technique at the time. There were also slight differences in the demographic make-up of the cohorts (eg, mean age), which were likely not of clinical relevance. A randomized controlled trial would be ideal but impractical, especially as our standard of care had changed from room air to $\mathrm{CO}_{2}$, based on improved patient comfort, safety, technologist preference, and anecdotal experience suggesting that $\mathrm{CO}_{2}$ was a better method for distention. ${ }^{8}$ Although the increased luminal fluid seen in the room air (DoD) cohort may have accentuated the differences in gas volumes, the overall luminal distention (ie, gas + fluid) was nonetheless considerably improved in the $\mathrm{CO}_{2}$ (UW) cohort.

In conclusion, this is the first quantitative study that assesses the true volumetric differences in colorectal distention between the room air and $\mathrm{CO}_{2}$ techniques. By using a novel QA tool that rapidly and objectively provides volumetric data, we have shown that $\mathrm{CO}_{2}$ is clearly superior to room air in terms of total colonic distention, even when adjusting for colon length. In addition, there are clear differences in the relative distention between supine and prone according to distention technique, with a logical explanation. This study provides objective evidence to the pre-existing biases in data suggesting the superiority of $\mathrm{CO}_{2}$. In conjunction with the other established advantages of improved safety, decreased postprocedural discomfort, and ease of use, our findings support the use of $\mathrm{CO}_{2}$ as the preferred front-line distention technique for CTC.

\section{References}

1. Pickhardt, PJ.; Kim, DH. CT colonography: principles and practice of virtual colonoscopy. Philadelphia: Saunders; 2010.

2. Pickhardt PJ. Screening CT colonography: how I do it. AJR Am J Roentgenol. 2007; 189:290. [PubMed: 17646453]

3. Dachman AH. Advice for optimizing colonic distention and minimizing risk of perforation during CT colonography. Radiology. 2006; 239:317. [PubMed: 16641349]

4. Kim, DH.; Pickhardt, PJ. Colonic distention for CT colonography. In: Pickhardt, PJ., editor. CT Colonography: principles \& practice of virtual colonoscopy. Philadelphia: Suanders; 2010. p. 131-147.

5. Kim SY, Park SH, Choi EK, et al. Automated carbon dioxide insufflation for CT colonography: Effectiveness of colonic distention in cancer patients with severe luminal narrowing. American Journal of Roentgenology. 2008; 190:698. [PubMed: 18287441]

6. Taylor SA, Halligan S, Goh V, et al. Optimizing colonic distention for multi-detector row CT colonography: Effect of hyoscine butylbromide and rectal balloon catheter. Radiology. 2003; 229:99. [PubMed: 12944595]

7. Burling D, Taylor SA, Halligan S, et al. Automated insufflation of carbon dioxide for MDCT colonography: Distension and patient experience compared with manual insufflation. American Journal of Roentgenology. 2006; 186:96. [PubMed: 16357385] 
8. Shinners TJ, Pickhardt PJ, Taylor AJ, et al. Patient-controlled room air insufflation versus automated carbon dioxide delivery for CT colonography. American Journal of Roentgenology. 2006; 186:1491. [PubMed: 16714635]

9. Hung PW, Paik DS, Napel S, et al. Quantification of distention in CT colonography: Development and validation of three computer algorithms. Radiology. 2002; 222:543. [PubMed: 11818626]

10. Pickhardt PJ. Incidence of colonic perforation at CT colonography: Review of existing data and implications for screening of asymptomatic adults. Radiology. 2006; 239:313. [PubMed: 16641348]

11. BLINDED:

12. Pickhardt PJ, Choi JR, Hwang I, et al. Computed tomographic virtual colonoscopy to screen for colorectal neoplasia in asymptomatic adults. New England Journal of Medicine. 2003; 349:2191. [PubMed: 14657426]

13. Fenlon HM, Nunes DP, Schroy PC, et al. A comparison of virtual and conventional colonoscopy for the detection of colorectal polyps. New England Journal of Medicine. 1999; 341:1496. [PubMed: 10559450]

14. Yee J, Akerkar GA, Hung RK, et al. Colorectal neoplasia: Performance characteristics of CT colonography for detection in 300 patients. Radiology. 2001; 219:685. [PubMed: 11376255]

15. Bretthauer M, Thiis-Evensen E, Huppertz-Hauss G, et al. NORCCAP (Norwegian colorectal cancer prevention): a randomised trial to assess the safety and efficacy of carbon dioxide versus air insufflation in colonoscopy. Gut. 2002; 50:604. [PubMed: 11950803]

16. Michel SJ, Pickhardt PJ, Kim DH, et al. Effect of colonic distention on superiority of supine versus prone views in screening computed tomographic colonography. Clin Imaging. 2007; 31:325. [PubMed: 17825740]

17. Buchach CM, Kim DH, Pickhardt PJ. Performing an additional decubitus series at CT colonography. Abdominal Imaging. 2011; 36:538. [PubMed: 21184064]

18. Khashab M, Pickhardt PJ, Kim DH, et al. Colorectal Anatomy in Adults At CT Colonography: Normal Distribution and the Effect of Age, Gender, and Body Mass index. Gastrointestinal Endoscopy. 2009; 69:AB275.

19. Hanson M, Pickhardt PJ, Kim DH, et al. Complete versus incomplete optical colonoscopy: Predictive factors based on clinical and virtual colonoscopy findings. Gastroenterology. 2006; 130:A47. 

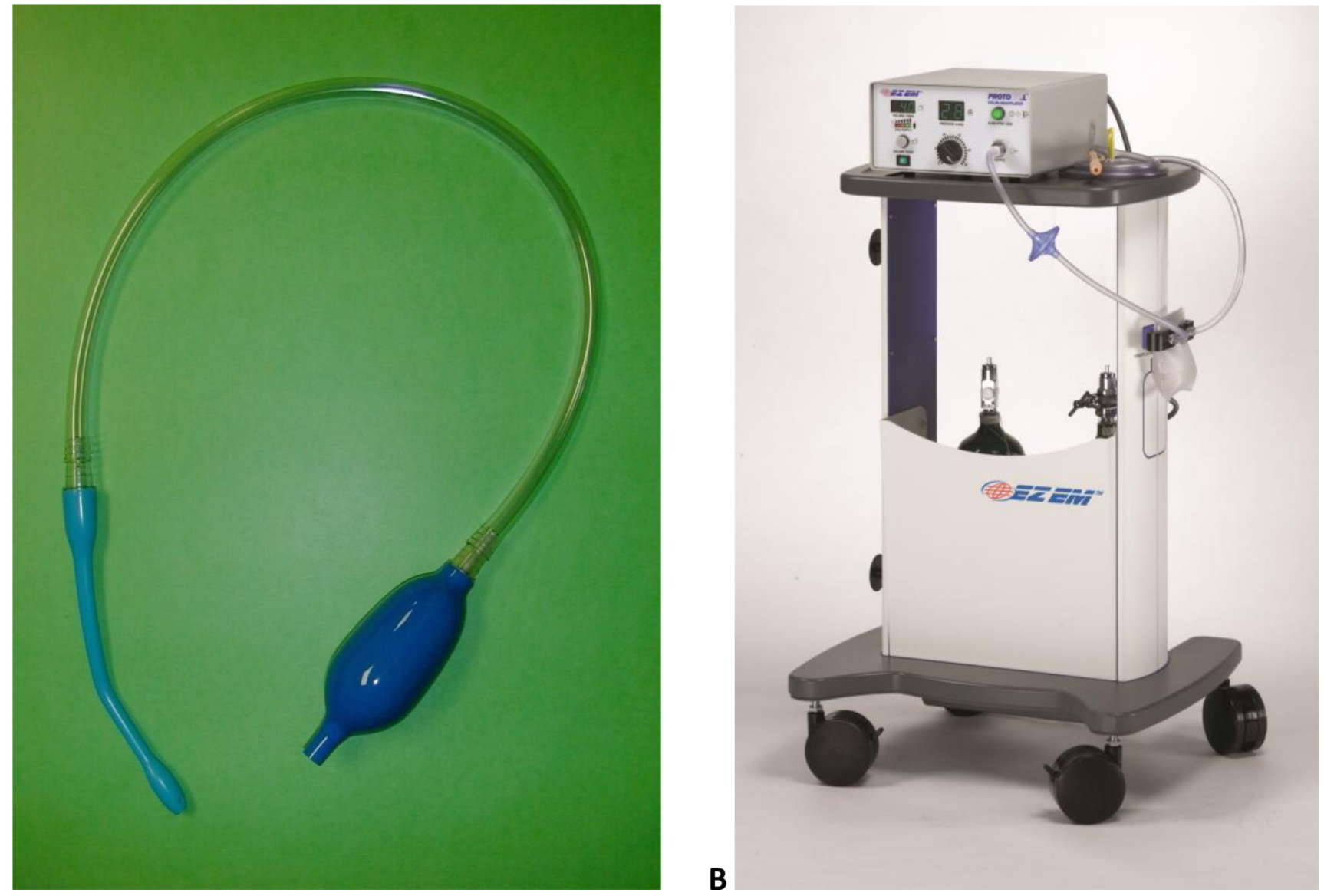

Figure 1. Colonic distention techniques

A. Apparatus for manual room air insufflation, consisting of a rectal catheter, tubing, and handheld bulb for air insufflation.

B. Automated $\mathrm{CO}_{2}$ device (PROTOCO $2 \mathrm{~L}$, Bracco Diagnostics), which controls rate and monitors intraluminal pressure for continuous low-pressure delivery as needed. 


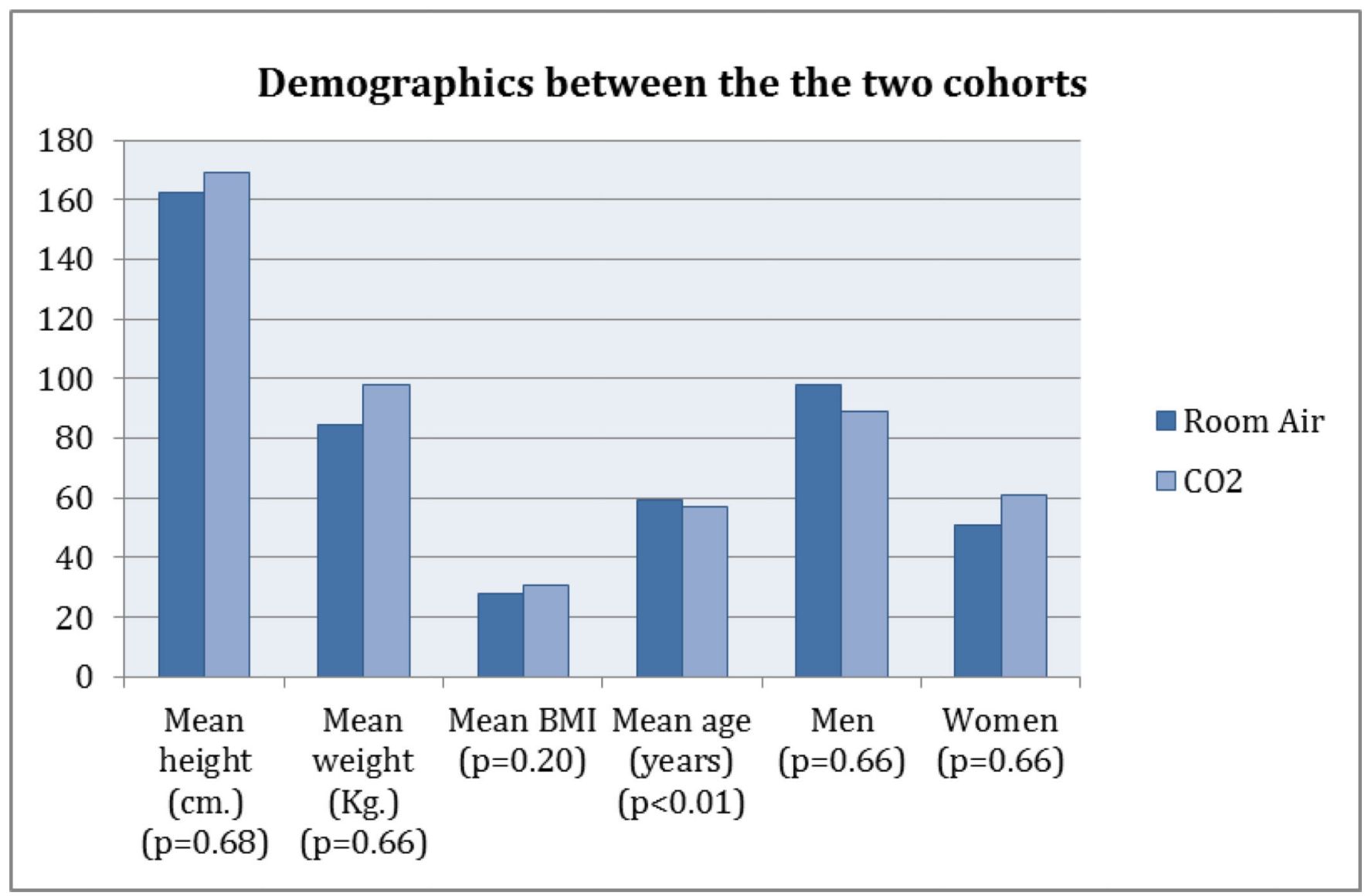

Figure 2.

Quantitative differences in the demographic make-up of the two cohorts. Only the age difference between the two groups was statistically significant with the DoD population being approximately 2 years older $(\mathrm{p}<0.01)$. This small age difference, however, is of doubtful clinical relevance. 
Mean total, fuild and gas volumes for the two groups

A
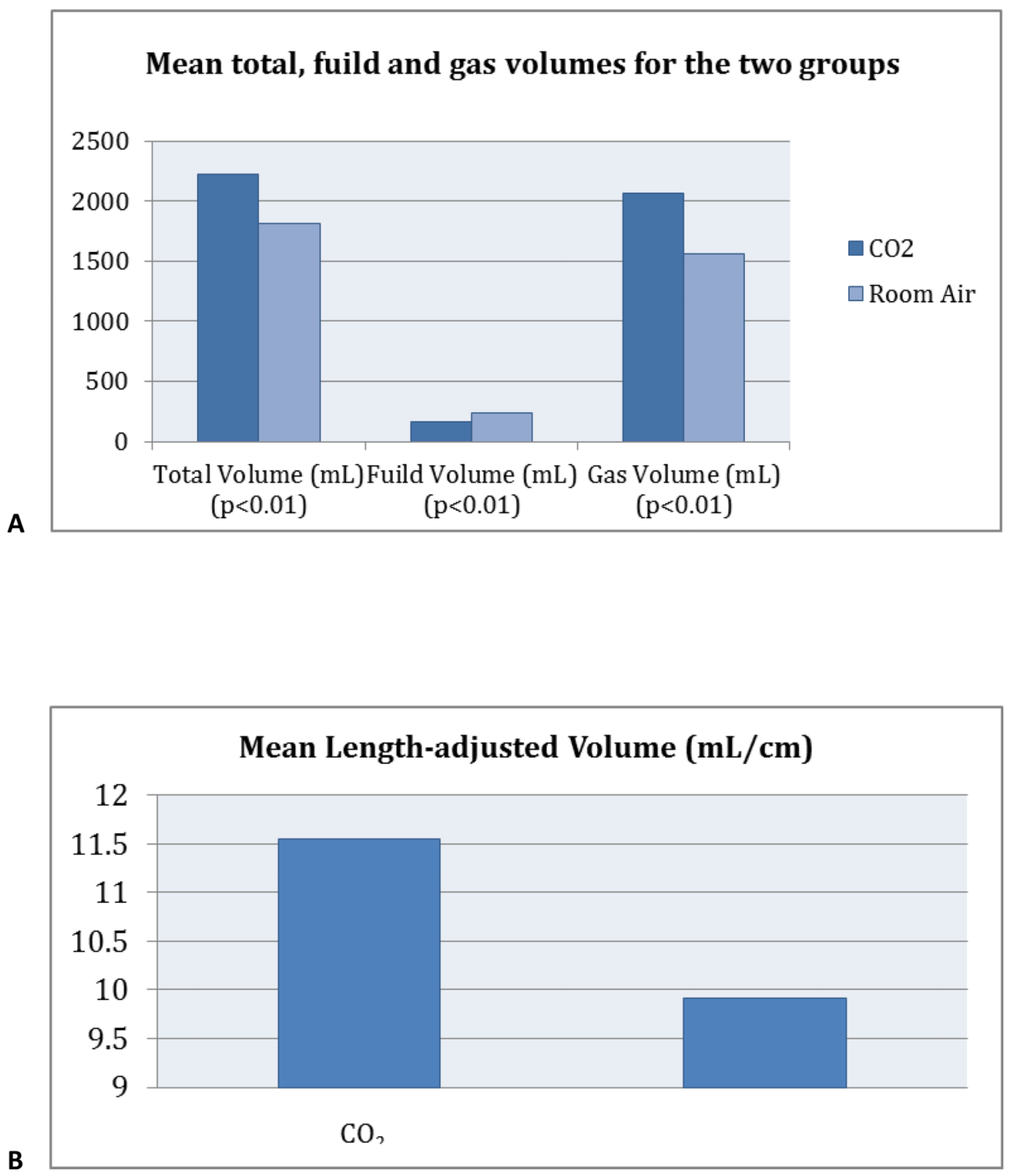

Figure 3. Colonic volumes between $\mathrm{CO}_{2}$ and room air cohorts with 150 subjects in each group A. Bar graph shows that mean non-length adjusted total colonic volume in the $\mathrm{CO}_{2}$ group is significantly greater than the room air cohort $(2222 \pm 686 \mathrm{~mL}$ vs. $1809 \pm 513 \mathrm{~mL} ; \mathrm{p}<0.01)$. Additionally, this shows the total amount of air between the two groups was statistically significant and the amount of fluid was also statistically significant with the DOD population having more residual fluid. $(\mathrm{p}<0.01)$. 
B. Bar graph shows that the length-adjusted mean total colonic volume $(\mathrm{mL} / \mathrm{cm})$ is also significantly greater in the $\mathrm{CO}_{2}$ group than room air $(11.6 \pm 2.6 \mathrm{~mL} / \mathrm{cm}$ vs. $9.9 \pm 2.4 \mathrm{~mL} / \mathrm{cm}$; $\mathrm{p}<0.01$ ) (note that the $\mathrm{y}$-axis does not begin at zero). 


\section{$\%$ Better Distention of Prone vs Supine in $\mathrm{CO}_{2}$ and Room Air}

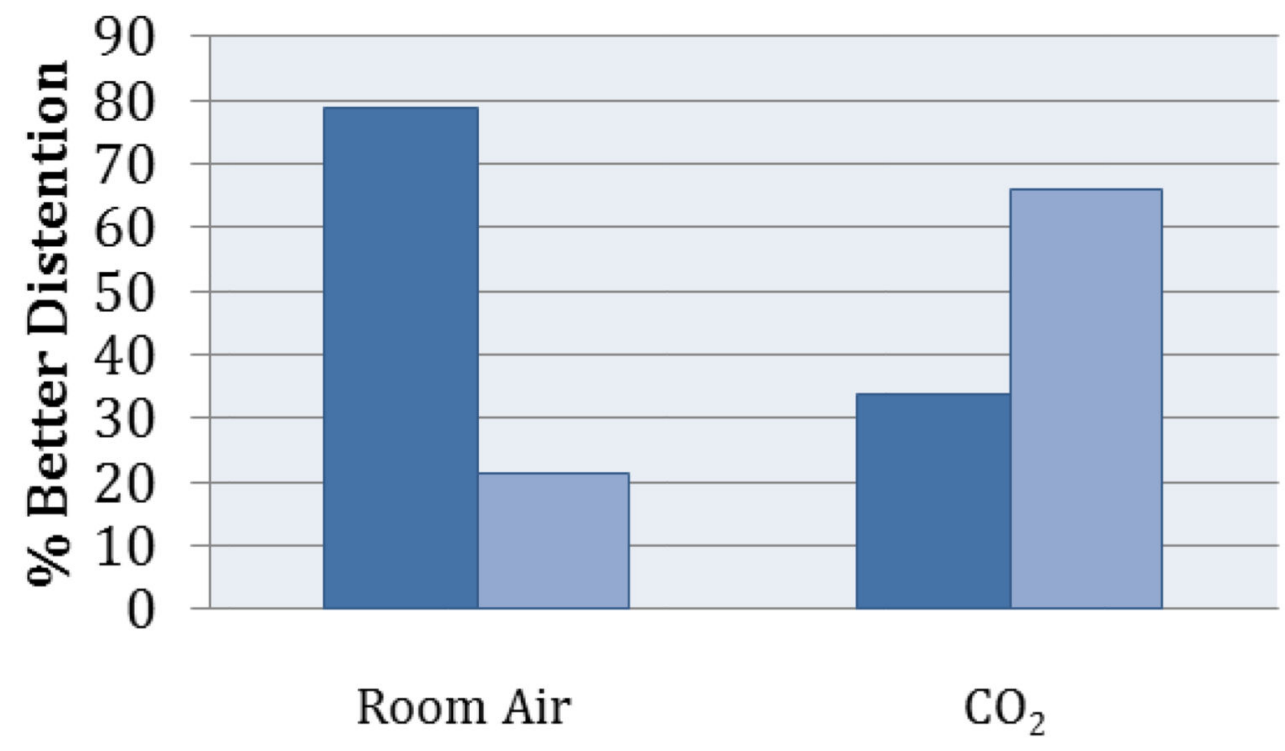

$\square$ Prone

Figure 4.

Bar graph shows which position (prone or supine) demonstrated better colonic distention between the room air and $\mathrm{CO}_{2}$ groups. Note that for room air, the prone view is typically better, whereas the opposite is true for $\mathrm{CO}_{2}$ (see discussion). 

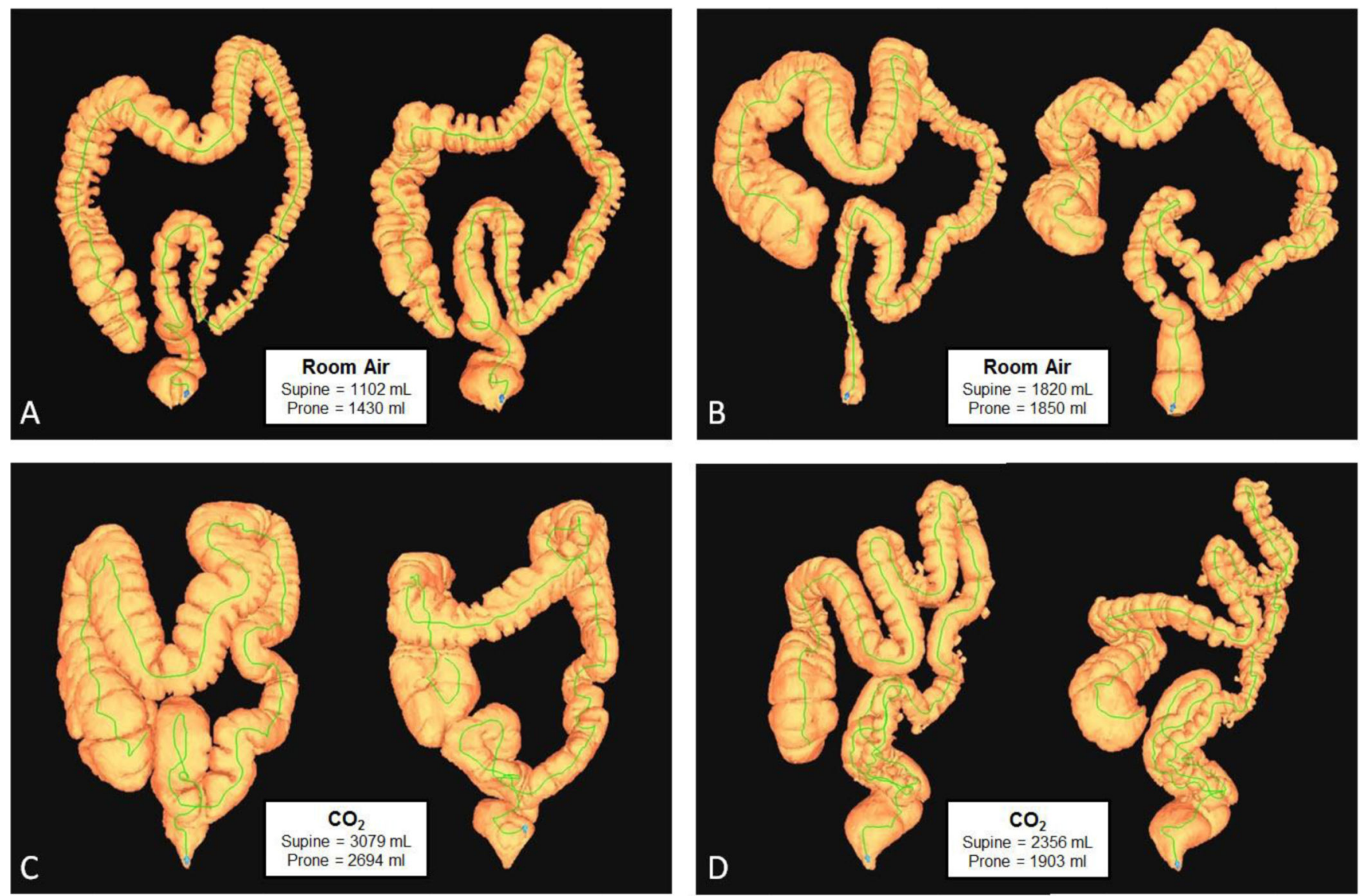

Figure 5.

$3 \mathrm{D}$ colon map images in four typical cases obtained with room air $(\mathbf{A}$ and $\mathbf{B})$ and $\mathrm{CO}_{2}(\mathbf{C}$ and $\mathbf{D})$ show the supine series on the left and prone series on the right for each case, including the luminal volume measurements. Note the improvement in distention on prone relative to supine for the room air cases ( $\mathbf{A}$ and $\mathbf{B}$ ), especially in the rectosigmoid region. For $\mathrm{CO}_{2}(\mathbf{C}$ and $\mathbf{D})$, the supine distention is generally superior to prone, especially in the transverse colon region. The overall degree of distention is also generally greater with $\mathrm{CO}_{2}$ compared with room air. 